\title{
ANÁLISE HISTÓRICA DO CLIMA EM UMA CIDADE DO NORDESTE BRASILEIRO
}

\section{Márcia Rosângela de SOUZA; Edivaldo Galdino FERREIRA²; Nadja Helaine de ARAÚJO³; Gil Dutra FURTADO 4}

\author{
${ }^{1}$ Engenheira Ambiental/Faculdade Internacional da Paraíba (FPB), Brasil. E-mail: \\ marciarosangelasousa@gmail.com
}

${ }^{2}$ Engenheiro Agrônomo/Universidade Federal da Paraíba (UFPB); Doutor em Fitotecnia/Universidade Federal Rural do Semiárido (UFERSA); Pesquisador III/Empresa Estadual de Pesquisa Agropecuária da Paraíba (EMEPA); Professor/FPB, Brasil. E-mail: edivaldogaldino@gmail.com

${ }^{3}$ Licenciada em Ciências Biológicas/UFPB; Mestra em Desenvolvimento e Meio Ambiente (PRODEMA)/UFPB, Brasil. E-mail: nadjahelainejp@hotmail.com

${ }^{4}$ Engenheiro Agrônomo/UFPB; Doutor em Psicobiologia/Universidade Federal do Rio Grande do Norte (UFRN); Agrônomo-Sócio da Cooperativa de Agronegócio (COOPAGRO), Brasil. E-mail: gdfurtado@hotmail.com

Resumo. O estudo do clima urbano representa um dos importantes temas emergentes socioambientais para a sociedade. O presente trabalho realizou o estudo do clima na cidade de João pessoa (Paraíba, Brasil), no período de 1963 a 1970 e 2001 a 2015, a partir das observações de temperatura do ar, umidade relativa e pluviosidade. A presente pesquisa utilizou o subsistema Termodinâmico e Hidrometeórico, onde seus canais de percepção são utilizados como subsídio teórico para a compreensão de eventos climáticos com efeitos geradores de impactos no âmbito social e ambiental. Os resultados obtidos mostraram que na cidade estudada o processo de urbanização tem alterado o clima, ressaltando a fragilidade do planejamento urbano. A partir dos resultados analisados, observouse variações entre dois períodos diferentes, onde em alguns anos ocorreram aumentos significativos.

Palavras-chave: Clima urbano; Temperatura; João Pessoa.

\section{HISTORICAL CLIMATE ANALYSIS IN A CITY OF NORTHEAST BRAZIL}

Abstract. The study of the urban climate represents one of the important emerging socioenvironmental themes for society. The present paper carried out the study of the climate in the city of João Pessoa (Paraíba, Brazil), from 1963 to 1970 and from 2001 to 2015, based on observations of air temperature, relative humidity and rainfall. The present research used the subsystem Thermodynamic and Hydrometeoric, where its channels of perception are used as theoretical subsidy for the understanding of climatic events with effects that generate impacts in the social and environmental scope. The results can show that in the studied city the urbanization process has altered the climate, 
highlighting the fragility of urban planning. From the results analyzed, it was possible to observe variations between two different periods, where significant increases occurred in some years.

Keywords: Urban climate; Temperature; João Pessoa.

\section{ANÁLISIS HISTÓRICO DEL CLIMA EN UNA CIUDAD DEL NORDESTE BRASILEÑO}

Resumen. El estudio del clima urbano representa uno de los importantes temas emergentes socioambientales para la sociedad. El presente trabajo realizó el estudio del clima en la ciudad de João Pessoa (Paraíba, Brasil), en el período de 1963 a 1970 y 2001 a 2015, a partir de las observaciones de temperatura del aire, humedad relativa y pluviosidad. La presente investigación utilizó el subsistema Termodinámico e Hidrometeórico, donde sus canales de percepción se utilizan como subsidio teórico para la comprensión de eventos climáticos con efectos generadores de impactos en el ámbito social y ambiental. Los resultados obtenidos pueden mostrar que en la ciudad estudiada el proceso de urbanización ha cambiado el clima, resaltando la fragilidad de la planificación urbana. A partir de los resultados analizados, fue posible observar variaciones entre dos períodos diferentes, donde en algunos años ocurrieron aumentos significativos.

Palabras clave: Clima urbano; Temperatura; João Pessoa.

\section{INTRODUÇÃO}

A partir do momento que o homem tomou consciência da independência das condições climáticas e dos resultados da sua deliberada intervenção no meio natural, como necessidade para o desenvolvimento social, ele passou a produzir e registrar o conhecimento sobre os componentes da natureza (MENDONÇA; DANNI-OLIVEIRA, 2007).

Carvalho (1982) traz à tona elementos importantes para a discussão e revisão de conceitos até então adotados em diversos trabalhos sobre climatologia urbana, em especial sobre as interações dinâmicas como os elementos do clima e da morfologia urbana em localidades situadas em clima quente-úmido, em baixa latitude.

Os resultados podem demostrar o quanto o processo da urbanização tem modificado o clima da cidade de João Pessoa, evidenciando a fragilidade dos parâmetros de planejamento que são estabelecidos na legislação urbana vigente. Com o crescimento da população, as áreas urbanas da cidade de João Pessoa também se expandiram, tanto horizontalmente como verticalmente.

O crescimento horizontal significou a impermeabilização do solo onde, com o aumento dessa impermeabilização, a carga de energia que atinge o solo é refletida de volta à atmosfera, formando assim uma ilha térmica em toda a sua extensão. 
Esse presente trabalho teve como objetivo analisar o clima na cidade de João Pessoa, Nordeste do Brasil, a partir da observação de temperatura, umidade relativa do ar e pluviosidade, levando em consideração a influência do crescimento urbano nas alterações do clima durante os períodos de 1963 a 1970 e 2001 a 2015.

\section{MATERIAL E MÉTODOS}

A metodologia utilizada foi baseada nas teorias de Monteiro (1976, 2003) sobre o estudo do clima das cidades.

Os procedimentos metodológicos do presente estudo consistiram no levantamento bibliográfico introdutório acerca da temática (GIL, 2002), seguido da coleta e sistematização do banco de dados disponibilizados pelo Instituto Nacional de Meteorologia (INMET, 2018).

\section{RESULTADOS E DISCUSSÃO}

O crescimento urbano na cidade de João Pessoa pode provocar mudanças climáticas. Assim, as medições ambientais podem proporcionar uma ferramenta importante para o desenvolvimento de metodologias para a mitigação dos fatores indesejáveis que venham a ocorrer.

De acordo com os dados do INMET, no período de 1963 a 1970 (Fig. 1A), observa-se uma variação de volume acumulado anual entre $1314,2 \mathrm{~mm}$ a 3888,4 $\mathrm{mm}$ durante os 8 anos registrados. No período de 2001 a 2015 (Fig. 1B), também se observa que ocorrera uma variação de 1178,3 mm/ano à 3053,7 mm/ano. Nestes períodos a média anual entre 1963 a 1970 foi de 2209,33 mm/ano e entre 2001 e 2015 foi de 1919,96 mm/ano.

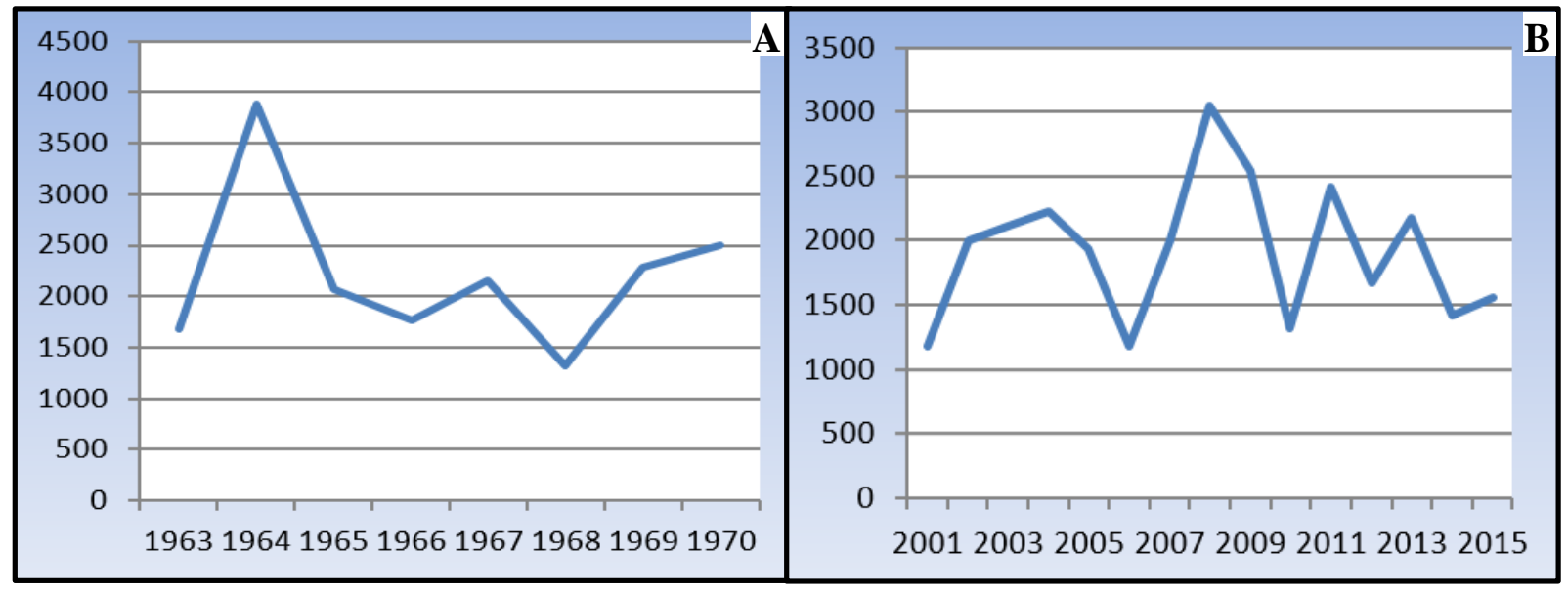

Figura 1. Níveis de precipitação na cidade de João Pessoa. A. 1963 a 1970; B. 2001 a 2015 (Fonte: INMET). 
No período de 1963 a 1970 (Fig. 2A), observa-se as variações de temperatura média anual, que oscilaram, aproximadamente, entre 26,5 (em 1969) e 25,2 (em 1965) e no período de 2001 a 2015 (Fig. 2B), observa-se as variações de temperatura média anual, que oscilaram, aproximadamente, entre 27,3 (em 2006 e 2010) e 24,1 (em 2014).

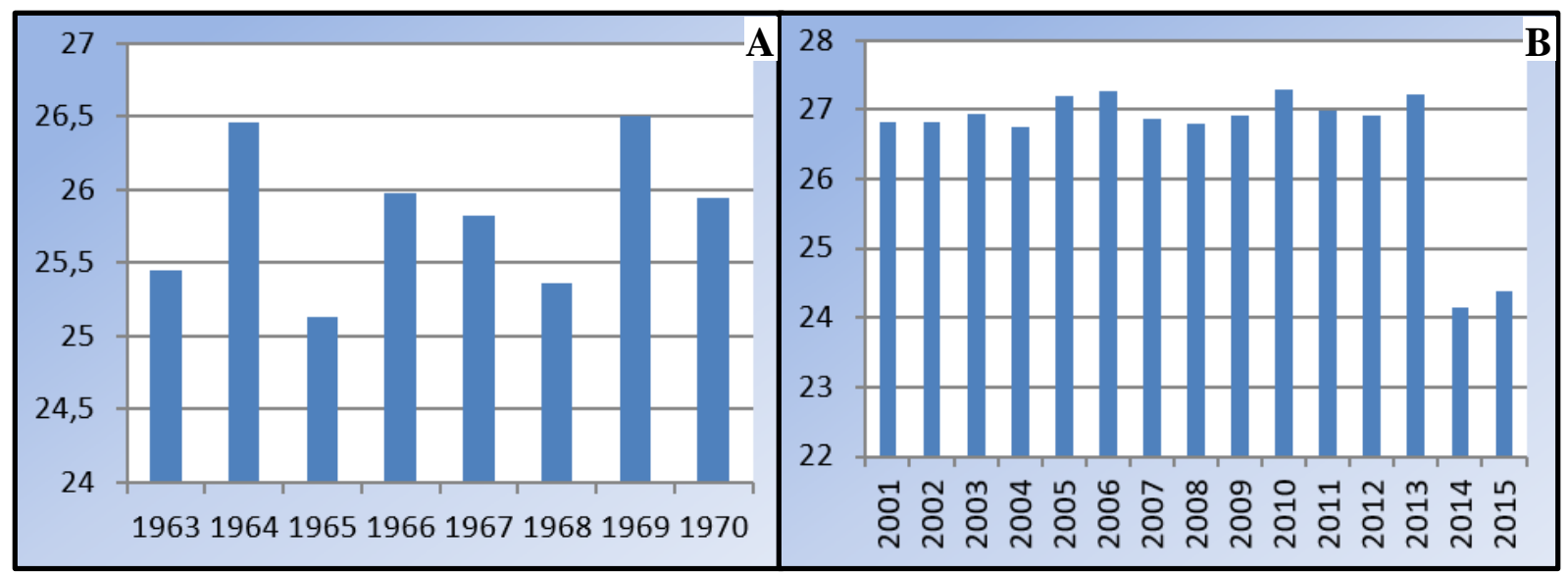

Figura 2. Níveis de temperatura média na cidade de João Pessoa. A. 1963 a 1970; B. 2001 a 2015 (Fonte: INMET).

No período de 1963 a 1970 (Fig. 3A), observa-se as variações das médias anuais de umidade relativa do ar, que oscilaram, aproximadamente, entre 82,5 (em 1970) e 75 (em 1969) e no período de 2001 a 2015 (Fig. 3B), observam-se as variações aproximadas, entre 78,5 (em 2002 e 2010) e 74,7 (em 2012).

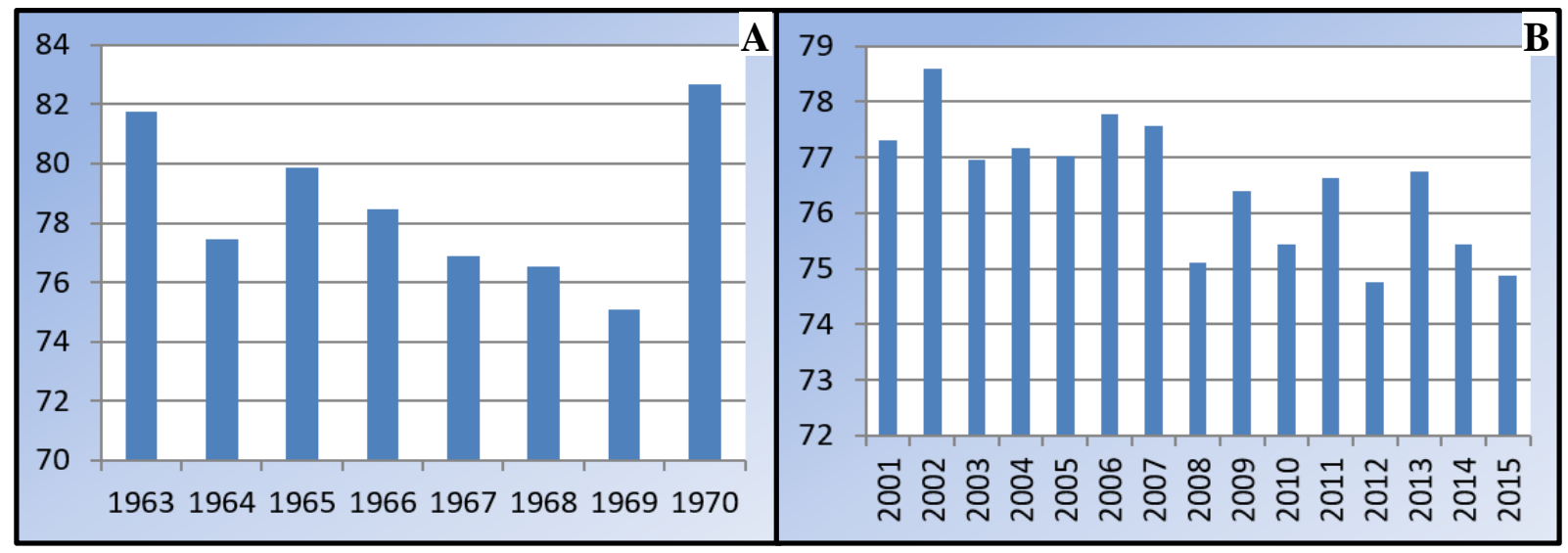

Figura 3. Níveis de umidade relativa do ar na cidade de João Pessoa. A. 1963 a 1970; B. 2001 a 2015 (Fonte: INMET). 
A cidade de João Pessoa é o principal centro financeiro e econômico do estado da Paraíba, com 811.598 habitantes, sendo considerada a oitava cidade mais populosa do Nordeste (IBGE, 2017).

Nas décadas de 1960, 1970 e 1980, a cidade estabeleceu seu ritmo de ocupação e os baixos planaltos são ocupados por conjuntos habitacionais que não se importam com as cabeceiras e vertentes dos rios, proporcionando um desequilíbrio que só começa a ser percebido a partir de 1990. A partir da descrição do relevo juntamente com o sítio urbano com áreas bastante impermeabilizadas, acarretam sobre si condicionantes de distúrbios, porém esses só são percebidos nos períodos em que a precipitação pluvial é maior de idade magnitude indicando chuvas mais concentradas, típicas do litoral paraibano no período denominado de inverno.

A temperatura mais elevada acaba por diminuir a pressão atmosférica, o que permite maior circulação de ventos e consequentemente aumentando assim a possibilidade de um núcleo que atrai os fluxos mais úmidos e, como a cidade de João Pessoa tem a leste seus limites com o oceano, logo, este passa a ser um grande agente de umidade. Levando em consideração a direção dos ventos de sudeste para noroeste, logo o continente como um grande atrativo das nuvens com maior umidade, em que estas condensam e se precipitam sobre o continente (ALVES FILHO; RIBEIRO, 2007; SANTOS et al., 2006).

A umidade relativa do ar é a relação entre o teor em vapor d'água que o ar contém e o teor máximo que poderia conter, estes sob a temperatura do ambiente. E a porcentagem de vapor d'água existente no ar em relação ao máximo que poderia existir na temperatura.

Foi evidenciado a variação do clima entre os períodos de anos distintos, sendo observado a média anual e as comparações de um período para outro, onde ocorreram variações na média dos anos estudados.

Devido ao crescimento urbano acelerado, os quais sofreram profundas alterações na sua superfície e nas suas formas horizontais e verticais o que resulta em fontes adicionais de calor provenientes das atividades antrópicas, provocando a redução de resfriamento evaporativo e convectivo em função da impermeabilização do solo, da diminuição da superfície coberta por vegetal e da redução da velocidade dos ventos pelo aumento da rugosidade superficial. 


\section{REFERÊNCIAS}

ALVES FILHO, A.P.; RIBEIRO, H. Configuração espacial de eventos de precipitação externa na região metropolitana de São Paulo: interações entre a ilha de calor e a entrada da brisa marítima. InterfacEHS, v. 2, p. 1-8, 2007.

CARVALHO, M.G.R.F. Estado da Paraíba: Classificação geomorfológica. João Pessoa: Ed. Universitária/UFPB, 1982.

GIL, A.C. Técnicas de pesquisa em economia e elaboração de monografias. 4 ed. São Paulo: Atlas, 2002.

IBGE (Instituto Brasileiro de Geografia e Estatística). Composição por municípios. 2017. Disponível em: < https://www.ibge.gov.br>. Acesso em: 23 jun. 2018.

INMET (Instituto Nacional de Meteorologia). Banco de Dados Meteorológicos para Ensino e Pesquisa. 2018. Disponível em: <http://www.inmet.gov.br>. Acesso em 25 jun. 2018.

MENDONÇA, F.; DANNI-OLIVEIRA, I.M. Climatologia: noções básicas e climas do Brasil. São Paulo: Oficina de Texto, 2007.

MONTEIRO, C.A.F. Teoria e Clima Urbano, Série Teses e Monografias, n. 25. São Paulo: Instituto de Geografia/USP, 1976.

MONTEIRO, C.A.F. Teoria e clima urbano: um projeto e seus caminhos. In: Clima urbano, São Paulo: Contexto 2003.

SANTOS, P.M.; PEREIRA FILHO, A.J.; CAMARGO, R.; FESTA, M.; FUNARI, F.L.; SALUM, S.T.; OLIVEIRA, C.T.; SANTOS, E.M.; LOURENÇO, P.R.; SILVA, E.G.; GARCIA, W.; FIALHO, M.A. Evolução climática na região metropolitana de São Paulo. In: CONGRESSO BRASILEIRO DE METEOROLOGIA, 14., Florianópolis. Anais... CBMET, 2006. p. 1-6. 